\title{
CONHECIMENTO SOBRE O LAZER NOS CURSOS DE EDUCAÇÃO FÍSICA DA CIDADE DE BELÉM
}

Recebido em: $25 / 07 / 2013$

Aceito em: 03/03/2014

\author{
Gustavo Maneschy Montenegro ${ }^{1}$ \\ Universidade Federal do Amapá (UNIFAP) \\ Macapá - AP - Brasil \\ Wagner Wey Moreira ${ }^{2}$ \\ Universidade Federal do Triângulo Mineiro (UFTM) \\ Uberaba - MG - Brasil
}

RESUMO: Esse artigo analisa os conhecimentos sobre o lazer desenvolvidos nos cursos de Educação Física da cidade de Belém. Na metodologia foram adotados como lócus da pesquisa os cursos de Educação Física da Universidade do Estado do Pará - UEPA e da Universidade Federal do Pará - UFPA. As fontes de análise elegidas foram os Projetos Político-Pedagógicos, as ementas e os Planos de Ensino das disciplinas que abordam o tema do lazer nas respectivas instituições. Como resultados, identificou-se que a UEPA procura discutir conteúdos relacionados às políticas públicas de lazer; direito ao lazer; lazer e qualidade de vida; lazer e sociedade. Na UFPA, evidenciou-se que a disciplina segue orientação didático-metodológica, enfatizando conhecimentos de cunho técnico aplicados ao lazer.

PALAVRAS CHAVE: Atividades de Lazer. Educação Física e Treinamento. Educação Superior.

\section{KNOWLEDGE ABOUT THE LEISURE IN COURSES OF PHYSICAL EDUCATION THE CITY OF BELEM}

ABSTRACT: This article analyzes the data about leisure at the Physical Education graduation courses at Belém. The investigation locus adopted were the Physical Education graduation courses from UEPA (University of the State of Pará) and UFPA (Federal University of Pará). The analysis sources were the political-pedagogical projects of the graduation courses and the educational plan - especially the topics that address specifically to the leisure in each institution. As a result, it was possible to identify that UEPA deliberates about the content related to the public policies of leisure,

\footnotetext{
${ }^{1}$ Mestre em Educação pela Universidade Federal do Pará; Docente do Curso de Educação Física da Universidade Federal do Amapá - UNIFAP. Membro do Núcleo de Estudos e Pesquisa em Educação Física, Esporte e Lazer - NEPEFEL, Coordenador da Linha de Pesquisa Educação Física e Lazeres.

2 Doutor em Educação - UNICAMP; Docente do Curso de Educação Física da Universidade Federal do Triângulo Mineiro - UFTM. É líder do Núcleo de Estudos e Pesquisas em Corporeidade e Pedagogia do Movimento - NUCORPO/CNPq.
} 
the right of the leisure, leisure and the quality of life, leisure and the society. At UFPA, it was clear that the discipline follows a didactic-methodological orientation.

KEYWORDS: Leisure Activities. Physical Education and Training. Education Higher.

\section{Introdução}

Esta pesquisa apresenta os principais resultados da Dissertação de Mestrado “Conhecimento sobre o lazer na formação de professores de Educação Física: um olhar sobre os cursos superiores das Universidades Públicas em Belém/PA”, a qual foi apresentada junto ao Programa de Pós-Graduação em Educação da Universidade Federal do Pará. Neste sentido, o estudo objetiva analisar os conhecimentos sobre o lazer desenvolvidos nos cursos de formação de professores de Educação Física nas Instituições de Ensino Superior (IES) Públicas da cidade de Belém.

Para início de conversa, é importante destacar que vem sendo reconhecida a relevância do lazer como uma esfera essencial da vida do ser humano, o qual pode contribuir para que as pessoas possam potencializar o seu desenvolvimento social, educacional e cultural.

Corrobora-se com Marcellino (2008, p. 11) quando afirma que é necessário compreender o lazer não apenas como uma vivência voltada para a diversão e para o entretenimento consumista, mas sim, é indispensável remetê-lo ao processo de políticas públicas, o qual, configura-se como um direito social, assim como a educação, saúde, trabalho e a moradia.

Para iniciar a discussão, vale ressaltar que o lazer se caracteriza como um campo de conhecimento multidisciplinar (ISAYAMA, 2010), podendo favorecer práticas interdisciplinares entre os profissionais das diferentes áreas que se dedicam a sua análise e reflexão (MONTENEGRO, 2012). 
Peixoto (2007) e Mascarenhas (2004) revelam que o lazer tem sido estudado por diversas áreas de conhecimento. A primeira identificou dezesseis campos do saber que tem produzido academicamente sobre o lazer, são eles a Sociologia, Direito, Filosofia, Etimologia, História, Geografia, Administração, Economia, Arquitetura e Urbanismo, Matemática, Enfermagem, Turismo e Hotelaria, Educação Física, Antropologia, Pedagogia e a Psicologia.

Mascarenhas (2004) afirma que o lazer é abordado como uma área de produção científica por diversos campos de conhecimento e por vários grupos de pesquisa no Brasil, o que explicita o seu crescimento e a sua importância na vida social.

Nesse contexto, emerge e difunde-se a discussão sobre o lazer, que deixa de ser compreendido apenas como um privilégio de algumas pessoas, passando a ganhar novos olhares e horizontes. Assim, destaca-se que o mesmo vem sendo pensado como ponto de partida para se analisar a própria sociedade e seus valores, já que não pode ser desvinculado de outros planos da vida social (ISAYAMA, 2010). Em decorrência disto, a formação de profissionais para atuar neste campo de estudo e intervenções surge como preocupação central de estudantes, profissionais e pesquisadores.

Em sua relação com a Educação Física, evidencia-se que o lazer se apresenta como um significativo campo de atuação profissional seja em clubes, escolas, políticas públicas de esporte e lazer, colônia de férias, na gestão de eventos e na pesquisa. Sendo assim, torna-se central, nas discussões atuais referentes ao lazer, conhecer o processo de formação docente voltado para a atuação nesses espaços.

No campo da produção teórica, o tema lazer tem sido bastante discutido nos curso de Educação Física no Brasil, principalmente pela crescente inserção de disciplinas específicas nos currículos de formação na área (ISAYAMA, 2002), pelo 
aumento de cursos de Pós-Graduação, Lato e Stricto Senso, e também pela ampliação do espaço destinado aos Estudos do Lazer em encontros acadêmicos da Educação Física, como, por exemplo, no Congresso Brasileiro de Ciências do Esporte (ISAYAMA, 2010).

Marcellino (2010) afirma que a associação entre a Educação Física e o lazer não é algo recente. O autor destaca que, tradicionalmente, a primeira presta serviços na área de recreação e lazer desde as décadas iniciais do século $\mathrm{XX}$, apesar de somente na década de 1960 a recreação tenha sido incluída formalmente na formação do profissional.

Para o autor, "a grande vinculação entre educação física e recreação/lazer é vista, no Brasil, no caminho histórico da ação profissional desde os anos de 1930" (MARCELLINO, 2010, p. 61). Com base nos estudos do autor, é possível perceber que existe um longo percurso de aproximação entre essas áreas em nosso país.

Esta questão pode ser facilmente percebida no estudo desenvolvido por Isayama e Souza (2006), uma vez que os autores identificaram, ao consultar os grupos de pesquisa cadastrados na plataforma lattes do site do Conselho Nacional de Desenvolvimento Científico e Tecnológico (CNPq), a existência de 81 grupos que discutem lazer, dos quais 36 estão ligados a cursos de Educação Física.

Um dos motivos que influenciam, segundo os autores, o aumento de pesquisas sobre este tema é o fato do lazer se configurar como um campo de atuação que tem crescido nos últimos anos, ao gerar não só oportunidades de intervenção profissional, mas também possibilidades de investigação e produção de conhecimento na área da Educação Física. 
Isayama (2010) afirma que mesmo com o crescimento de produções científicas no âmbito do conhecimento Educação Física/Lazer, os estudos dedicados à reflexão sobre a formação dos profissionais são escassos, fato este que clama a necessidade de investir em pesquisas que se propõem discutir e revelar como o lazer é abordado no interior desses cursos de graduação.

Autores como Schawarz (2007), Isayama (2002), Marcellino (2003, 2010) e Valente $(1993,1997)$, ao investigarem a temática, identificaram que a forma como o lazer é abordado nos currículos de Educação Física segue uma perspectiva predominantemente instrumental, ou seja, a formação se assenta em uma discussão superficial, centrada na vivência corporal descontextualizada, tendo assim, o intuito de “treinar” os profissionais a reproduzir atividades lúdicas.

Compartilha-se com o pensamento de Werneck (2000, p. 144) quando afirma que a formação na área do lazer deve estar alicerçada na busca de:

[...] sujeitos comprometidos com o processo de construção do saber, sujeitos que questionem a realidade, que perguntem pelo sentido de seu exercício profissional, que assumam uma atitude reflexiva face aos processos sociais e às contradições do nosso meio, fazendo do lazer não um mero (e alienante) produto a ser consumido, mas uma possibilidade lúdica, crítica, criativa e significativa a ser vivenciada com autonomia e muita responsabilidade.

Destarte, discutir o conhecimento sobre o lazer a ser inserido na formação em Educação Física é importante, pois o profisssional é responsável por dinamizar um espaço lúdico, em que as atividades de lazer possam estar atentas para a formação educacional crítica dos participantes (MONTENEGRO, 2012).

No que concerne ao contexto da formação profissional em lazer, tomando como referência os cursos de Educação Física da cidade de Belém, é possível perceber uma crescente atenção para com a presença dessa temática na formação. Atualmente, é 
possível constatar que três, dos quatro cursos de Educação Física existentes na cidade, destinam pelo menos uma disciplina focada para o exame deste objeto e duas instituições apresentam brinquedotecas em seus campi, as quais se caracterizam como mais uma oportunidade de estágio e vivência profissional na área do lazer.

Embora se reconheça que o espaço reservado ao lazer nestas instituições ainda é pequeno, considera-se que estas iniciativas como ações que revelam a gradativa importância dada ao tema na Região Norte e, por conseguinte, no Estado do Pará.

Por meio destas análises, percebeu-se a necessidade de investir em estudos que tragam a tona questões relacionadas à formação nos cursos de Educação Física na cidade de Belém voltada ao lazer, pois, apesar do crescente número de pesquisas sobre estas instituições ${ }^{3}$, as produções não realizaram reflexões mais profundas acerca da inserção do lazer no interior destes currículos.

Em meio aos questionamentos levantados o problema central que conduziu a pesquisa foi: quais conhecimentos sobre o lazer são desenvolvidos nos cursos de formação de professores de Educação Física nas Instituições de Ensino Superior (IES) Públicas da cidade de Belém?

Nesta linha de raciocínio, se faz necessário destacar que, em termos da relevância acadêmica e social do conhecimento produzido na perspectiva dos "Estudos do Lazer", em especial para o estado do Pará, esta pesquisa pretende cobrir possíveis lacunas existentes na produção do conhecimento a respeito das questões político-pedagógicas em relação à temática, pois mesmo com os currículos de Educação Física apresentando

\footnotetext{
3 Atualmente, podem ser identificadas algumas Dissertações de Mestrado que procuraram analisar as propostas de formação apresentadas pelos Cursos de Educação Física na cidade de Belém, e até mesmo do Estado do Pará: Treptow (2008), Aguiar (2009), Brito Neto (2009), Coelho (2010), Mota (2010), Gordo (2011) e Aranha (2011). Porém, apesar de ser um número crescente e significativo, nenhuma delas se dedicou a refletir sobre a abordagem do lazer no interior desses cursos.
} 
discussões sobre o lazer, existem poucos estudos na Região Norte e no Estado do Pará que se dedicam a este debate.

\section{Metodologia}

Este estudo assumiu os pressupostos da Pesquisa Qualitativa que, segundo Lüdke e André (1986), trata-se de um modelo de investigação, no qual envolve a obtenção de dados a partir do contato direto do pesquisador com a situação estudada, enfatizando mais o processo do produto e se preocupando em explicitar a perspectiva dos participantes.

De acordo com as autoras, na pesquisa qualitativa, "os pesquisadores não se preocupam em buscar evidências que comprovem hipóteses definidas antes do início do estudo. As abstrações se formam ou se consolidam basicamente [...] à medida que o estudo se desenvolve" (LÜDKE; ANDRÉ, 1986, p. 13).

Como a intenção era estar o mais próximo do objeto de investigação, optou-se pela pesquisa qualitativa, pois ela permite "uma imersão do pesquisador na vida e no contexto" (CHIZZOTTI, 2005, p. 81) do objeto pesquisado e, vale-se da interpretação do fenômeno, levando em consideração toda sua subjetividade, com o intuito de decodificar e de revelar sua complexidade (LÜDKE; ANDRÉ, 1986).

Esta pesquisa tomou como lócus de investigação as duas universidades públicas da cidade de Belém que apresentam o curso de Educação Física, são elas: Universidade do Estado do Pará - UEPA e Universidade Federal do Pará - UFPA.

Embora já obtendo o conhecimento de que existam quatro IES na cidade, que apresentam o curso, a escolha por essas duas instituições como objeto de investigação ocorreu a partir da vivência na graduação e por se tratar das universidades públicas da 
cidade, as quais são referências na formação e no fomento de debates acadêmicos relacionados à Educação Física e ao Lazer.

Para tanto, foi realizada uma investigação do tipo Documental, a qual, de acordo com Gil (1991, p. 51), "vale-se de materiais que não receberam ainda um tratamento analítico, ou que podem ser reelaborados de acordo com os objetivos da pesquisa".

Esta modalidade de investigação científica se sustenta por meio da análise de documentos para obter informações do objeto em estudo, ou seja, "sempre que uma pesquisa se utiliza apenas de fontes documentais (revistas, documentos legais, arquivos em mídia eletrônica, diz-se que a pesquisa possui estratégia documental)" (APPOLINÁRIO, 2009, p. 85).

Lüdke e André (1986, p. 38) entendem documento como "quaisquer materiais escritos que possam ser usados como fontes de informação sobre o comportamento humano". Estes incluem desde leis e regulamentos, normas, pareceres, relatórios, memorandos, diários pessoais, fotografias, programas de disciplinas, discursos, roteiros de programas de rádio, de televisão e arquivos escolares, sendo, portanto, materiais com fontes primárias, os quais possuem dados originais que nunca receberam análise acadêmico-científica.

Para a realização desta pesquisa, o primeiro passo foi o contato com a coordenação dos cursos, a fim de obter autorização para a execução da investigação. Mediante a autorização, foi solicitado o Projeto Político-Pedagógico - PPP de cada instituição investigada a fim de identificar a presença de disciplinas voltadas a discutir o tema do Lazer.

Como critério de inclusão das disciplinas na pesquisa, foi determinado que fossem selecionadas somente as que apresentassem, em seu título, a palavra "lazer". 
Com isso, identificou-se, tanto na UEPA, como na UFPA, apenas uma disciplina que aborda especificamente a temática do Lazer, que são denominadas, respectivamente, de "Estudos do Lazer" e de "Recreação e Lazer na Sociedade".

Após essa identificação, a próxima ação foi à solicitação das ementas e dos planos de ensino destas disciplinas. Ao todo, os cursos disponibilizaram as ementas requeridas e quatro planos de ensino, sendo dois da UEPA, referentes ao ano de 2010 e dois da UFPA, um do ano de 2010 e o outro de 2011.

Para analisar o material coletado utilizou-se a técnica da Análise Documental, a qual é definida por Lüdke e André (1986, p. 38) como um procedimento que "busca identificar informações factuais nos documentos a partir de questões ou hipóteses de interesse".

As autoras afirmam que o propósito da análise documental é "fazer inferências sobre os valores, os sentimentos, as intenções e a ideologia das fontes ou dos autores dos documentos" (LÜDKE; ANDRÉ, 1986, p. 40). Com essa técnica, é possível apreender o problema a partir da própria expressão dos indivíduos, as formas de produção destes, sejam por meio de redações, cartas e qualquer material escrito.

A análise dos dados da pesquisa ocorreu mediante o cruzamento do referencial teórico sobre a formação de profissionais para a atuação no lazer e as interpretações de termos chave presentes nos documentos que evidenciavam a proposta de formação desenvolvida pelas instituições. Assim, foram abstraídas categorias que orientaram a reflexão e a discussão realizada, tais como: políticas públicas de lazer; direito ao lazer; lazer e qualidade de vida; lazer e sociedade, programação e execução de atividades voltada para o lazer, aplicação didático-metodológica. Ressalta-se que as interpre- 
tações são sustentadas e evidenciadas por meio dos fragmentos contidos nos documentos, os quais serão explicitados a seguir.

\section{Resultados e Discussões}

Esta etapa do texto destina-se a apresentar e analisar os conhecimentos sobre o lazer inseridos nos programas das disciplinas que abordam este tema nos cursos de Licenciatura em Educação Física da cidade de Belém.

Inicialmente, ao analisar as propostas de formação apresentadas pelas instituições, a partir dos Projetos Político-Pedagógicos dos cursos, foi possível identificar, em vários pontos dos documentos, proeminências em relação ao campo do lazer, fato que evidencia certa finalidade das instituições em fomentar a formação de seus graduandos para esse âmbito de sua atuação profissional.

No caso do Projeto Político-Pedagógico do curso de Educação Física da UEPA, como exemplo, destaca-se o interesse da instituição em responder as demandas de atuação profissional nos seguimentos das "academias, nas escolinhas de futebol e nas diversas ações de lazer” (UEPA, 2007, p. 30).

A intenção de abordar o lazer pode ser identificada no conjunto das competências profissionais desejadas pela instituição, em que o lazer aparece em dois tópicos: no primeiro, referente à "atitude ética e compromisso com a democratização da construção histórica no âmbito das práticas corporais, esportivas e do lazer" e também associado à "capacidade de relacionar as práticas corporais, esportivas e do lazer nos diversos campos de trabalho" (UEPA, 2007, p. 37). 
Destaca-se que o lazer é apontado também como um dos principais conhecimentos presentes nessa formação, o que se torna evidente no seguinte trecho do documento:

\begin{abstract}
O desenvolvimento da educação física se estabelece também nas práticas de lazer. Entendido como prática que valoriza o tempo livre do homem, mas que, ao mesmo tempo, discute qual tempo livre que o homem tem na sociedade, quais são as reais práticas de lazer que a sociedade pode realizar e de que forma se estabelece essas práticas, se são de livre criação ou manipuladas por padrões da indústria cultural (UEPA, 2007, p. 33).
\end{abstract}

Ao consultar o Projeto Político-Pedagógico do curso da UFPA, também pode ser identificada a presença do lazer em alguns pontos do documento. Isso revela que ambas apresentam a intenção de discutir a temática do lazer no seu processo de formação docente.

Na UFPA, a preocupação com a inclusão do lazer enquanto componente curricular é manifestada, por exemplo, em meio ao entendimento da Educação Física como uma área de "conhecimento e imprescindível, componente curricular das escolas no processo global do ser humano, gera novos desafios e novos campos de trabalho, quer seja na esfera do lazer, do esporte ou da Educação Física em geral" (UFPA, 2006, p. 2).

O lazer aparece como um dos espaços de intervenção profissional do professor, o qual tem nas "danças, lutas, esportes, ginásticas, jogos e diferentes formas de recreação e lazer na intenção de atuar, de fato, no ato educativo escolar que oriente crítica e criativamente, o aluno-cidadão" (UFPA, 2006, p. 4).

A mesma intenção em abordá-lo também pode ser vista em um dos objetivos específicos do curso, no qual a Educação Física é entendida como uma área do conhecimento: 
desenvolver conhecimento em temas que versem sobre jogos, esportes, ginásticas, danças e atividades físicas de lazer (UFPA, 2006, p. 19).

Com base na leitura dos documentos, foi possível perceber a presença do lazer como conteúdo a ser discutido na proposta de formação apresentada pelas instituições, o que demonstra o reconhecimento de uma importante área para atuação do profissional de Educação Física.

Esse fato se articula com as ponderações de Isayama (2002) quando indica que a Educação Física no Brasil tem se dedicado, cada vez mais, a incluir nos currículos análises relativas ao campo de estudos sobre o lazer.

Entretanto, a mesma preocupação com as reflexões sobre o lazer não pode ser vista no que concerne à disposição das disciplinas no desenho curricular de ambas as instituições, pois, apesar de estar presente em alguns pontos dos Projetos PolíticoPedagógicos analisados, o lazer aparece timidamente nos currículos dos cursos, em apenas uma disciplina, fato este que não reflete a mesma intenção com a discussão expressa nos documentos.

Isayama $(2002,2003,2010)$ afirma que essa forma de abordá-lo é constante nos cursos de Educação Física do país, nos quais o tema acaba sendo tratado, apesar de ser colocado como um eixo importante, em apenas uma disciplina, de carga horária quase sempre reduzida, dificultando uma formação mais aprofundada sobre a questão.

Em sua pesquisa de doutorado, o autor concluiu que existe "uma média de 1,76 disciplinas por curso" o que expressa "o pequeno espaço para a difusão do conhecimento sobre recreação e lazer no interior desses currículos” (ISAYAMA, 2002, p. 58).

Esta questão também é apontada por Campos e Silva (2010). Os autores realizaram um levantamento nos sites de algumas universidades brasileiras com o 
objetivo de verificar como as disciplinas sobre o lazer aparecem distribuídas no desenho curricular das instituições.

Como critério de escolha, eles elegeram as dez universidades mais bem colocadas na lista do Ministério da Educação pelo Índice Geral de Cursos da Instituição (IGC). Dentre as quais, somente cinco ofertavam o curso de Educação Física, que são a Universidade Federal do Estado de São Paulo (UNIFESP), Universidade Federal de Viçosa (UFV), Universidade Federal de Minas Gerais (UFMG), Universidade Federal do Rio Grande do Sul (UFRGS) e a Universidade Federal do Rio de Janeiro (UFRJ).

Ao consultar os desenhos curriculares dos cursos, os pesquisadores concluíram que:

\begin{abstract}
As disciplinas relacionadas ao campo do lazer aparecem timidamente na grade curricular desses cursos. Na UNIFESP não há registro de disciplinas ligadas à área; já nas outras quatro IES, há variação de uma a três disciplinas obrigatórias presentes nas respectivas grades curriculares. [...] conforme visto acima há nos referidos cursos - nos quais as respectivas instituições figuram entre as melhores do país -, uma desatenção com o campo do lazer, campo esse que vem se configurando como promissor tanto no que se refere ao mercado de trabalho quanto no que diz respeito à produção de conhecimento (CAMPOS; SILVA, 2010, p. 155).
\end{abstract}

Amparado pelo estudo supracitado, conclui-se que embora exista uma ampliação de discussões acerca do lazer na área da Educação Física, fenômeno esse que segundo Isayama (2002) tem crescido principalmente a partir dos anos 1990, o espaço de discussão que envolve a temática ainda é pequeno nos cursos de Educação Física do Brasil.

A mesma realidade se observa na UEPA e na UFPA, pois é possível constatar que a inserção deste conhecimento em seus desenhos curriculares é pequena. Sendo assim, avalia-se ser necessária uma ampliação do espaço destinado à difusão de conteúdos referentes ao lazer, pois realizar uma formação detalhada, sobre um assunto 
bastante profuso, em apenas uma disciplina, apresenta-se como um desafio para as instituições.

Com relação à proposta de formação apresentada na ementa da disciplina Estudos do Lazer, do curso de Educação Física da UEPA, foi possível identificar que a mesma exibe a intenção de abordar o lazer a partir dos seguintes aspectos: enfoque sóciohistoricos e tendências na produção do conhecimento no campo do lazer; o lazer como campo transdisciplinar de formação humana, intervenção profissional e direito social.

Tomando como referência os conhecimentos sobre o lazer presentes nos planos de ensino da disciplina, é possível perceber o destaque para os seguintes temas a serem discutidos na formação dos alunos: políticas públicas do lazer, os direitos legais ao lazer, práticas políticas de lazer para o desenvolvimento humano e qualidade de vida, lazer e sociedade, formação e desenvolvimento para a atuação - o Público e os Projetos Sociais.

Considerando as temáticas expressas nos documentos analisados, identificou-se que a principal intenção da proposta de formação da disciplina "gira" em torno de uma reflexão do lazer enquanto um direito social e como política pública.

Sobre esta questão, é possível identificar, na atualidade, a presença do lazer em diversas leis ${ }^{4}$ que o garantem como direito social, como política pública e o tratam como dever do Estado em proporcionar espaços e vivências nesse âmbito de nossas vidas.

\footnotetext{
${ }^{4}$ Montenegro (2011) ressalta que o lazer é abordado também na Política Nacional para a integração das Pessoas com Deficiência - Decreto lei $\mathrm{n}^{\circ} 3.298$, Legislação do Sistema Único de Saúde - SUS, lei $\mathrm{n}^{\circ}$ 8.080 , na lei $\mathrm{n}^{\circ} 10.216$, que dispõe sobre a proteção e os direitos das pessoas portadoras de transtornos mentais.
} 
Marcellino (2008) revela que o lazer aparece como direito social na Constituição Brasileira de 1988, sendo mencionado no Título II, Capítulo II e artigo $6^{\circ}$, “a educação, a saúde, a alimentação, o trabalho, a moradia, o lazer, a segurança, a previdência social, a proteção à maternidade e à infância, a assistência aos desamparados, na forma desta Constituição" (BRASIL, 1988).

Em meio ao debate, avaliou-se que a inserção destas discussões na proposta da disciplina da UEPA se justificava pelo fato do lazer aparecer enquanto direito social em várias leis brasileiras, o que, além de proporcionar uma visão mais ampla do mesmo, pode explicitar ao discente que o lazer é um bem social, o qual deve ser acessível a todas as pessoas em suas diferentes faixas etárias.

Apesar de incluir essas reflexões na formação, constatou-se que a disciplina oferece pouco espaço para a discussão de conhecimentos de cunho metodológico e para a construção crítica e reflexiva de um repertório de atividades lúdicas que possam embasar a atuação desse profissional.

Considera-se que podem ser incluídos mais espaços formativos que tenham o intuito de auxiliar na construção de um saber técnico por parte do professor, fato que pode ser alcançado por meio de organização de programações em lazer ou, como ensina o educador Antônio Nóvoa (1992), do contato com profissionais mais experientes que já atuam nessa área.

Na UFPA, ao observar os conhecimentos presentes na ementa da disciplina Recreação e Lazer na Sociedade, pode-se identificar que a sua proposta de formação apresenta a intenção de abordar conteúdos de ordem didático-metodológicos, ao enfatizar aspectos como programação de atividades de esporte e lazer em conjunto com 
organizações comunitárias e a aplicação didático-metodológica no contexto da Educação Física escolar e não escolar.

Com relação à organização dessa disciplina, a partir dos planos de ensino foi identificado que a disciplina não dissemina apenas conhecimentos de cunho "práticos", embora esses ainda apareçam com bastante evidência.

Nas unidades de conteúdos destacadas nos documentos, podem ser constatadas ênfases para: modelos e paradigmas de planejamento, programação, execução e avaliação de ações de lazer e recreação; planejamento e aplicação das atividades recreativas e de lazer em instituições de ensino.

Essa perspectiva também está presente nos próprios objetivos inseridos nos planos de ensino, nos quais é possível verificar a intenção de discutir temas como: sistematizar possibilidades metodológicas de intervenção no âmbito do lazer e recreação; executar possibilidades de intervenção no âmbito do lazer e vivenciar alternativas metodológicas para o trato do lazer em espaços formais e não-formais.

Todavia, percebe-se que a proposta de formação desenvolvida pela disciplina na UFPA não se limita à abordagem desses conteúdos, embora esse seja o seu foco central de discussão. Isso é afirmado em virtude de se ter encontrado, nos próprios planos de ensino, a presença dos seguintes conhecimentos: lazer e trabalho na sociedade; processo histórico do surgimento do lazer e da recreação; concepções de lazer e recreação; conteúdos culturais do lazer e atividades recreativas.

Mediante as evidencias analisadas, verificou-se que a disciplina enfatiza conteúdos didático-metodológicos relacionados ao Lazer. Todavia, não se trata de uma formação limitada a aspectos instrumentais, mas que procura agregar fundamentação teórica que auxilie a atuação do professor nos espaços de lazer. 
Isayama (2010) afirma que a formação do profissional em lazer não deve negar a construção de um conhecimento técnico, entretanto, o autor ressalta a necessidade de se estabelecer um processo formativo não de mera reprodução de jogos e brincadeiras, fundamentados em verdadeiros "manuais" de recreação.

Corrobora-se com o pesquisador quando argumenta que os cursos de Educação Física devem criar espaços para a construção de um repertório de atividades vivenciadas e refletidas socialmente a partir da ação/reflexão/ação de professores e alunos envolvidos no processo de formação, a qual "deve possibilitar o domínio de conteúdos que tem de ser socializados, por meio do entendimento de seus significados em diferentes contextos e articulações interdisciplinares" (ISAYAMA, 2010, p. 13).

Para tanto, a formação de profissionais voltada ao âmbito do Lazer precisa promover o conhecimento de processos de investigação que auxiliem no aperfeiçoamento de ações político pedagógicas, ao se focar o desenvolvimento de práticas educativas lúdicas, críticas e criativas.

A partir desse olhar lançado a respeito da temática do Lazer no curso de Educação Física da UFPA, foi possível constatar que a mesma segue essa orientação didático-metodológica, pois a instituição ressalta aspectos como a aplicação e execução de atividades e programações de lazer.

Estas são as principais direções estabelecidas para o campo da formação profissional em Lazer desenvolvida pelos cursos de Educação Física, das universidades públicas da cidade Belém. Com isso, espera-se ter demonstrado as diferentes formas de abordagem empreendidas pelos cursos, no que tange a discussão e compreensão desse objeto. 


\section{Considerações Finais}

No caminhar desta pesquisa, partiu-se da crítica a ênfase "didáticometodológica" que, historicamente, assumiu a discussão do lazer como conhecimento trabalhado na formação em Educação Física. Assim, deparou-se com diversos autores que em suas produções acadêmicas revelaram constantes fragilidades nos processos formativos de profissionais para atuação nos espaços de lazer.

Em síntese, foram identificadas duas perspectivas de pensar a formação na área do lazer nos cursos de Educação Física de Belém. Na UEPA, a discussão do lazer tem o seu núcleo voltado para reflexões de temas como: Políticas públicas; Formação humana e intervenção profissional; Enfoque sociohistórico do lazer; lazer e sociedade; Políticas públicas e direitos legais ao lazer. Assim, demonstra-se que a proposta formativa não ocorre na lógica do "fazer pelo fazer".

Apesar de incluir essas reflexões na formação, foi possível verificar que a disciplina oferece pouco espaço para a discussão de saberes de cunho metodológico e para a construção de um repertório de atividades lúdicas, que possam embasar a atuação desse profissional.

Advoga-se haver a necessidade de incluir mais espaços formativos, os quais possam auxiliar na construção do conhecimento técnico e de um repertório de atividades refletidas culturalmente e socialmente, a partir das experiências de vida dos alunos e professores.

No que se refere ao curso de Educação Física da UFPA, foi possível perceber conhecimentos sobre o lazer que seguem orientação de cunho didático-metodológico, destacando-se temas como: Programação e execução de atividades voltadas para o lazer; Modelos e paradigmas de planejamento, programação, execução e avaliação de ações de 
lazer e recreação; Construção e aplicação de intervenção pedagógica; Aplicação didático-metodológica no contexto da educação física escolar e não escolar.

Apesar de privilegiar esse foco, compreende-se que a disciplina não trabalha o lazer de forma pragmática, apenas instrumental, por meio de uma reprodução acrítica de "técnicas" recreativas e na ausência de construção teórica. Essa afirmação decorre do fato de se ter identificado a presença dos seguintes conteúdos: Concepção e conceitos de lazer; Lazer e trabalho na sociedade: tempo livre e tempo disponível; Processo histórico do surgimento do lazer e da recreação; Animação Sócio-Cultural; e, Lazer e educação.

A inserção destes temas na proposta da disciplina tem o intuito de fundamentar uma intervenção profissional mais crítica e ampliada por parte do professor o que, como ponto de vista, caracteriza-se como um avanço na formação do profissional.

É importante destacar que o espaço destinado à discussão do lazer nas instituições é pequeno, fato esse que se coloca como um limite para a formação. Nesse sentido, coloca-se como sugestão para as instituições a necessidade de ampliar as oportunidades de debate dessa temática nos currículos dos cursos, o que pode ser alcançado por meio da inclusão de disciplinas com discussões que envolvam políticas públicas de lazer, experiências de extensão e elaboração de projetos nesse campo de conhecimento. Portanto, com as reflexões realizadas no transcorrer desta pesquisa, espera-se ter suscitado novas interpretações e novas possibilidades de compreensão desse objeto, sobretudo, no que concerne a formação profissional ligada à área do Lazer. 


\section{REFERÊNCIAS}

AGUIAR, Eliane do Socorro de Sousa. Análise do processo de reformulação do projeto político pedagógico do curso de educação física da UEPA: ação regulatória e emancipatória. 2009. 101f. Dissertação (Mestrado em Educação)- Centro de Ciências Sociais e Educação, Universidade do Estado do Pará, Belém, 2009.

APPOLINÁRIO, F. Dicionário de metodologia científica: um guia para a produção do conhecimento científico. São Paulo: Atlas, 2009.

ARANHA, Otávio Luiz Pinheiro. Currículos de formação de professores de educação física no Estado do Pará: conteúdos curriculares, concepções pedagógicas e modelos de profissionalidade. 2011. 217f. Dissertação (Mestrado em Educação)Instituto de Ciências da Educação, Universidade Federal do Pará, Belém, 2011.

BRASIL. Constituição (1988). Constituição da República Federativa do Brasil, 1988. Brasília: Senado Federal, Centro Gráfico, 1988. 292p.

Decreto n. 8.080 de 19 de Setembro de 1990. Diário Oficial [da] República Federativa do Brasil, Brasília, DF, 20 set. 1990. p. 8-16

Decreto no 3.298, de 20 de dezembro de 1999. Diário Oficial [da] República Federativa do Brasil, Brasília, DF, 21 dez. 1999. p. 25-40

Decreto n. 10.216, de 6 de Abril de 2001. Diário Oficial [da] República Federativa do Brasil, Brasília, DF, 6, abr. 2001. P. 15-30

BRITO NETO, Anibal Correia. O Impacto das diretrizes curriculares nacionais nos projetos políticos pedagógicos dos cursos de graduação em Educação Física do Estado do Pará. 2009. 129f. Dissertação (Mestrado em Educação)- Centro de Ciências Sociais e Educação, Universidade do Estado do Pará, Belém, 2009.

CAMPOS, Priscila Augusta; SILVA, Sílvio Ricardo da. Formação profissional em Educação Física e suas interfaces com o lazer. In: ISAYAMA, Helder (Org.). Lazer em Estudo: currículo e formação profissional. Campinas: Papirus, 2010. p. 143-161.

CHIZZOTTI, A. Pesquisa em ciências humanas e sociais. São Paulo: Cortez, 2005.

COELHO, Higson Rodrigues. Formação de professores de educação física: limites, contradições e possibilidades da prática como componente curricular dos cursos de graduação do Estado do Pará. 2010. 116f. Dissertação (Mestrado em Educação)- Centro de Ciências Sociais e Educação, Universidade do Estado do Pará, Belém, 2010.

GIL, Antônio Carlos. Como elaborar projetos de pesquisa. São Paulo: Atlas, 1991.

GORDO, Margarida do Espírito Santo Cunha. A formação profissional em Educação Física no Pará e a aspiração discente. 2011. 189f. Dissertação (Mestrado em Educação)-Instituto de Ciências da Educação, Universidade Federal do Pará, Belém, 2011. 
ISAYAMA, Helder. Ferreira. Recreação e Lazer como integrantes de currículos dos cursos de graduação em Educação Física. Tese (Doutorado em Educação Física). Campinas: Faculdade de Educação Física da Unicamp, 2002.

Recreação e lazer na formação profissional em Educação Física: reflexões sobre o currículo. In: WERNECK, C. L.; ISAYAMA, H. F. (Org.). Lazer, recreação e educação física. Belo Horizonte: Autêntica, 2003. p. 173-214.

. SOUZA, A. P. T. Lazer e Educação Física: análise dos grupos de pesquisa em lazer cadastrados na plataforma lattes do CNPQ. In: EFDeportes.com, Revista Digital, Buenos Aires, Año 11, n. 99, ago. 2006. Disponível em: $<$ http://www.efdeportes.com/efd99/cnpq.htm>. Acesso em: 18 Jun. 2010.

. Formação Profissional no âmbito do lazer: desafios e perspectivas. In: ISAYAMA, Helder (Org.). Lazer em Estudo: currículo e formação profíssional. Campinas: Papirus, 2010. p. 9-25.

LÜDKE, Menga; ANDRÉ, Marli. Pesquisa em educação: abordagens qualitativas. São Paulo: EPU, 1986.

MARCELLINO, Nelson Carvalho. Formação e desenvolvimento de pessoal em políticas públicas de lazer e esporte. In: MARCELLINO, Nelson Carvalho (Org.). Formação e desenvolvimento de pessoal em lazer e esporte: Para atuação em políticas públicas. Campinas: Papirus, 2003. p. 9-17.

Subsídios para uma política pública de lazer: o papel da administração municipal. In: MARCELLINO, Nelson Carvalho (Org.). Políticas públicas de lazer. Campinas, SP: Editora Alínes, 2008, p. 11-16.

A relação teoria e prática na formação profissional em lazer. In: ISAYAMA, Helder (Org.). Lazer em Estudo: currículo e formação profissional. Campinas: Papirus, 2010. p. 59-85.

MASCARENHAS, Fernando. O lazer como prática da liberdade: uma proposta educativa para a juventude. Goiânia: Ed. UFG, 2004.

MONTENEGRO, Gustavo Maneschy. Políticas Públicas do lazer: um enfoque na formação. In: EFDeportes.com, Revista Digital, Buenos Aires, Año 16, n. 156, Mayo de 2011. Disponível em: <http://www.efdeportes.com/efd156/politicas-publicas-dolazer-na-formacao.htm.> Acesso em: 25 Maio 2011.

Conhecimento sobre o lazer na formação de professores de Educação Física: um olhar sobre os cursos superiores das universidades públicas em Belém/PA. 2012. 190f. Dissertação (Mestrado em Educação)-Instituto de Ciências da Educação, Universidade Federal do Pará, Belém, 2012. 
MOTA, Joselene Ferreira. A formação inicial dos professores de Educação Física da Rede Municipal de Ensino de Belém: a organização do trabalho pedagógico para o ensino da Educação Física na Educação Infantil. 2010. 149f. Dissertação (Mestrado em Educação)- Centro de Ciências Sociais e Educação, Universidade do Estado do Pará, Belém, 2010.

NÓVOA, Antônio. Formação de Professores e Profissão Docente. In: NÓVOA, Antônio (Org.). Os Professores e sua formação. Lisboa: Dom Quixote, 1992. p.15-33.

PEIXOTO, Elza. Levantamento do Estado da Arte nos Estudos do Lazer: (Brasil) Século XX e XXI - alguns apontamentos. Educ. Soc. Campinas, v. 28, n. 99, p. 561586, maio/ago. 2007. Disponível em: <http: //WWW.cedes.unicamp.br>. Acesso em: 11 nov. 2010.

UFPA. Universidade Federal do Pará. Projeto Político-Pedagógico do Curso de Educação Física. Belém: UFPA, 2006, 150p.

UEPA. Universidade do Estado do Pará. Projeto Político-Pedagógico do Curso de Educação Física. Belém. UEPA, 2007, 175p.

SCHWARZ, Liamara. A disciplina lazer e recreação na formação de professores de Educação física: estudo sobre alguns tratos curriculares em Universidades Estaduais do Paraná. Dissertação (Mestrado em Educação Física).Florianópolis/SC: Centro de Desportos da UFSC, 2007.

TREPTOW, Anahy Garcia. A Formação do professor de educação física no Pará: o que revela a história do currículo do Curso de Educação Física da Universidade Estadual do Pará? 2008. 128 f. Dissertação (Mestrado em Educação)-Instituto de Ciências da Educação, Universidade Federal do Pará, Belém, 2008.

VALENTE, Márcia C. A disciplina Recreação e Lazer no currículo de formação de profissionais de Educação Física: o que dizem e o que fazem os professores do Nordeste do Brasil. 1993. 160f. Dissertação (Mestrado em Educação Física)- Faculdade de Educação Física, Universidade Estadual de Campinas, Campinas, 1993.

Lazer e recreação no currículo de educação física. Maceió: Edufal, 1997.

WERNECK, C. L. Lazer, Trabalho e Educação: relações Históricas, questões contemporâneas. Belo Horizonte: Ed. UFMG: CELAR-DEF/UFMG, 2000.

\section{Endereço dos Autores:}

Gustavo Maneschy Montenegro

Wagner Wey Moreira

Conjunto Teleamapá, Av. 02, No 125 ap. D

Jardim Marco Zero

Macapá - AP - 68900-072

Endereço Eletrônico: gustavo_maneschy@hotmail.com 